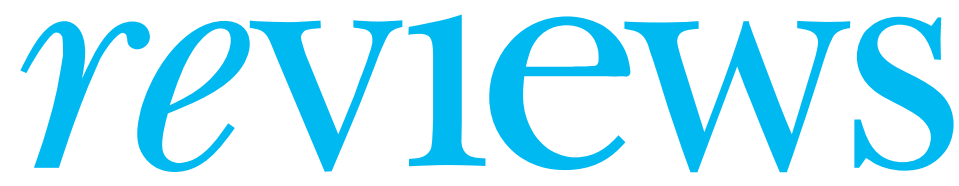

BOOKS • CD ROMS • ART •WEBSITES $\bullet$ MEDIA $\bullet$ PERSONAL VIEWS $\bullet$ SOUNDINGS

\section{The Foundling Museum}

40 Brunswick Square, London WC1N 1AZ www.foundlingmuseum.org.uk

Rating: $\star \star \star \star$

tigma, separation, segregation, and loss - the Foundling Museum, which opened in London's Bloomsbury last month, tells a sad tale. How could it be otherwise? Among the most affecting objects are the small tokens mothers attached to their babies when they left them to the care of the Foundling Hospital, hoping one day to reclaim the children they could not support.

Between its inception in 1741 and its closure in 1953 the hospital, founded by the childless philanthropist Thomas Coram, looked after 27000 deserted children. Admitted when they were under a year, babies were baptised by the hospital, given a new name, put out to a wet nurse or foster mother, and then readmitted between the ages of three and six and cared for until they were 21. Only a few were ever reclaimed by their mothers.

Criteria for admission drawn up in 1801 specified: "illegitimacy, first child, healthy baby under one, mother of good character." Admission days were held when mothers drew balls out of a bag. A white ball meant their baby would be examined and admitted if healthy, red meant the waiting list, and a black ball meant rejection. In the early years about two-thirds of applicants were turned away.

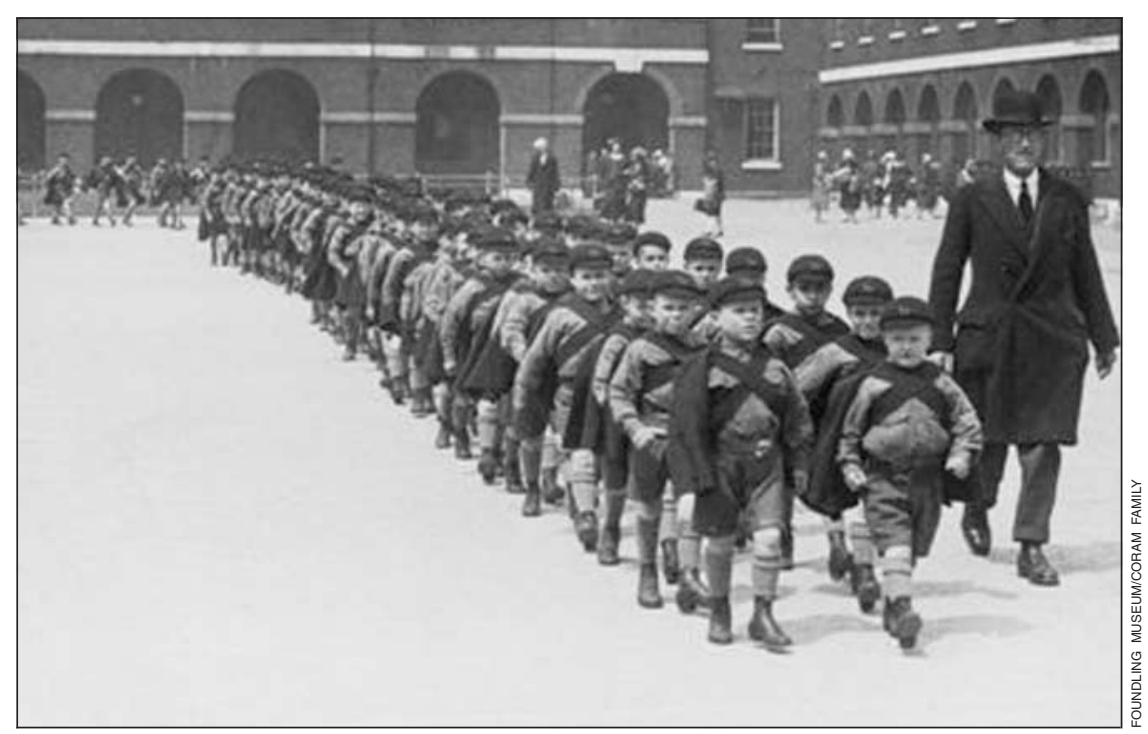

Boys march out of the hospital for the last time before relocation to Surrey, 1926

And admission did not guarantee a healthy future. Developmental defects resulting from malnutrition were common, and, the museum catalogue notes, "a general lack of protein meant most foundlings grew up to be noticeably shorter than average."

The hospital had its own school, dispensary, and medical service-Dr Richard Mead, physician to King George II, was an early patron who gave his services free-and contact with the outside world was discouraged. Children were told to keep at least 12 feet (3.7 metres) from the gates. They wore uniform, had uniform haircuts, slept in large dormitories known as wards, and walked everywhere crocodile fashion. "Boys and girls only met once a year at the Twelfth Night dance. And we were never told the facts of life," recalls one former resident in a taped account.

Admitted to the hospital in March 1926 when the hospital had moved from its original site in Bloomsbury to Redhill, Mary Bentley describes being stripped of all her clothes, having her head shaved, and being put in a bath which, in retrospect, she finds "rather demeaning." But she says, "I loved school and had many friends I have kept in touch with and the medical care was excellent." Mary traced her birth mother and kept in touch with her until her death. "I didn't like her but I did look after her."

In another taped account, Harold Tarrant, now 92, who was admitted to the Foundling Hospital in winter 1912, recalls terrible food, bullying, canings, complete segregation, a brutal headmaster, and inspection by the

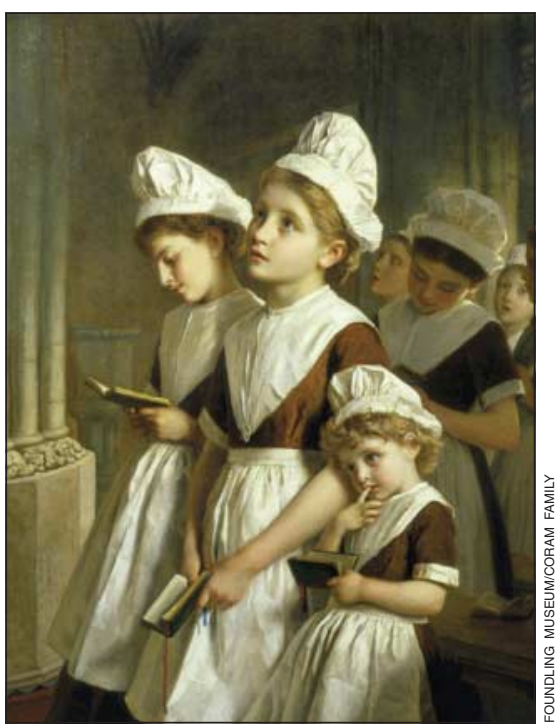

Foundling Girls at Prayer in the Chapel by Sophie Anderson (18th century)

Duke of Connaught, a vice president of the hospital. When he was 10 he developed an abscess on his shoulder and was treated in $\mathrm{St}$ Bartholomew's Hospital for a month, and remembers a nurse bringing him a Christmas parcel. It was the first he had had.

He made lifelong friends at the Foundling Hospital and became an engineering apprentice but he says, "It was not a life I would have wished on anyone else."

John Caldicott was admitted in 1936 after his mother lost her job in a laundry and could not face bringing up her baby in a workhouse. He was still there when the hospital closed in 1953 and the remaining 50 children were fostered. He remembers "an almost Victorian regime" which did not allow children to forget their origins. "You were made to understand you were very much second class citizens, born out of wedlock, and that our mothers had been given a chance to repair their lives." He left with no qualifications, was apprenticed to a radio company, had his own family and traced his birth mother and five half brothers.

"They [the hospital] did give me enough education to get me by and retire a relatively happy man," he says. "But there is a sadness about my life in the Foundling Hospital and without doubt there are scars. I am never able to show affection to my sons," he says. "I regret my lost childhood and theirs."

Joanna Lyall freelance journalist, London j.lyall@ision.co.uk 
Stolen Innocence: A Mother's Fight for JusticeThe Story of Sally Clark John Batt

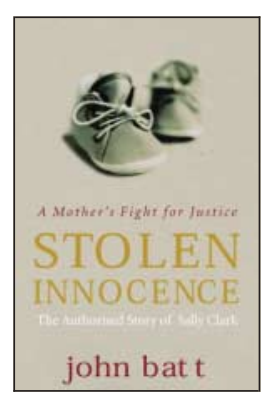

Ebury Press, £14.99, pp 336 ISBN 0091900700 www.randomhouse.co.uk

Rating: $\star \star \star \star$

$\Gamma$

his book is a disturbing read. It is a terrible indictment of the criminal system, the legal profession, and our own experts.

Solicitor Sally Clark was convicted in November 1999 of the murder of her two children, purely on the basis of medical expert testimony, and sentenced to life imprisonment. The case attracted a high media profile, but since her conviction, later overturned on appeal, it is the role of the medical experts that has been on trial. As witnesses for the prosecution, they described retinal haemorrhages, bruises, broken bones, and injuries to the spinal cord. These were either seen in error or were consequences of the postmortem examinations. "I have never known a case where so many apparent findings have turned to dust on critical examination," said one defence expert, paediatric pathologist Professor Peter Berry, at the original hearing (p 190).

The main prosecution expert failed to inform the court or the defence that multiple postmortem specimens, including the cerebrospinal fluid, grew Staphylococcus aureus. A medical knight of the realm, Professor Sir Roy Meadow, told the court that the chance that these deaths were natural cot deaths was 1 in 73 million. The statistic was quoted in every headline and is widely believed to have led to Sally Clark's conviction. Yet his basic understanding of the use of statistics was rudimentarily wrong and he was incorrect by several orders of magnitude.

The prosecution experts appear to have acted collectively, each in the cartel convinced of the authority of the other, and each convinced of Sally Clark's guilt. One expert, forensic pathologist Professor Michael Green, states elsewhere that $40 \%$ of all sudden infant deaths are murder (p 143). This is despite the fact that the incidence of SIDS has fallen precipitously following guidance on sleeping positions. Such experts are the hawks of child abuse. They see it everywhere. How are we to know if we should believe them or not?

In the original trial one by one the key forensic findings "turned to dust," in Profes- sor Berry's words. But reading John Batt's chilling book, the odd thing is that you feel that, once someone had pressed the button and the decision to try Sally Clark was made, the fact that the evidence dropped away was almost irrelevant. Somehow the momentum remained even when the substance had disappeared. The jury had seen one authoritative middle aged doctor after anotherfigures who might have treated them as children and filled them with confidencestate that this woman was guilty. The experts' facts had evaporated but their belief remained-and that was what the jury saw. The jury convicted on the authority of these doctors - and on the collective authority that medicine wields in our society.

And it is this that is the most disturbing. As individual doctors we are not responsible for the high regard in which our profession is held. It is a legacy that has built up over generations. When we make use of that authority we are its guardians. We have it only on trust. We rely on it in almost every consultation because without it we are nothing. The doctors being judged in this book acted like zealots. They professed certainty where there was doubt. They failed to retract when honesty required it. They betrayed that trust. And it does seem to me like a terrible thing to have done.

\section{Kevin Barraclough general practitioner,}

Painswick, Gloucestershire

kbarraclough@ehotspot.co.uk

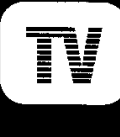

\section{Young Doctors}

ITV 1, Mondays at $10 \mathrm{pm}$ from 12 July to 16 August

Rating: $\star$

$\mathrm{M}$ y medical school was always keen to remind us that passing yourself off as a doctor was a serious offence. But this six part fly-on-the-wall documentary series, following a group of third year medical students at Southampton University as they start their clinical training, has no such qualms about pretending to be something above its station. This series opts for the sexy title Young Doctors and in doing so sets the tone for the show, which seems more interested in high ratings and sensationalism than offering an informative or revealing perspective on medical students' lives.

We are introduced to Camilla who "knows what she wants-she wants to party, she wants to be in charge, and she wants to become a surgeon"; and Barney, "a vicar's son from Salisbury who works hard but likes to play even harder." This is more like an episode of Friends than a documentarywith each character reducible, in the producers' eyes, to a snappy, throwaway line.

We see Barney studying hard at his desk as the soundtrack plays celestial organ music. Cut to pounding pop anthems and "dishy" Barney, rather the worse for wear, strutting his stuff on the dance floor. The social lives of these poor students get as much airtime as their clinical studies, and it soon gets dull.

When we do get to see the "young doctors" on the wards things start to pick up, partly because the real stars of the show are the patients. Mr M looks on unfazed as blood gushes from his arm while Jacob frantically tries to stem the flow. "You've got to learn," says Mr M, sharing a smile with the sheepish-looking Jacob. There's also humour, when Lizzy tells the camera that her first clerking "wasn't too bad considering she was deaf, partially blind, and Swiss."

What do we learn from this type of programme? Sadly, not much. But there is the odd revealing moment, such as when we hear that Lizzy may not go on to practise medicine: "Medicine is a hard degree, but it's [just] a degree," she tells us. "I'll see at the end if I still am keen to take that career path, and if not I'll just travel the world and be a beach bum."

Bruno Rushforth final year medical student, Manchester University, and BMJ Clegg Scholar brushforth@bmj.com

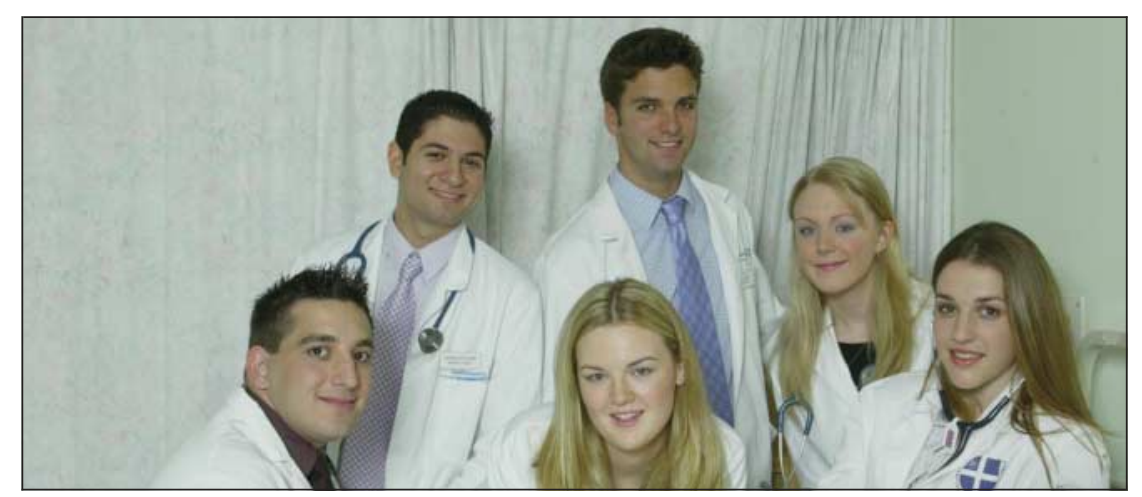




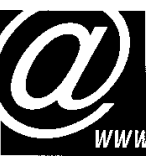

\section{Website gives media the tough treatment}

$\mathrm{M}$ any doctors and scientists have long been concerned about the quality of medical reporting. Now, in a direct response to what they see as spin and distortion, a group of academics and clinicians in Australia has launched a website that evaluates media coverage of new medical treatments. Their particular goal is to counter the public relations blitz that often accompanies product launches.

The website (www.mediadoctor.org.au), which went live two weeks ago, evaluates press articles using a three-star rating system and criteria that include how benefits, harms, and costs are reported, as well as the independence of information sources, and whether there is any disease mongering.

Its founders, from the Newcastle Institute of Public Health in New South Wales, hope to raise awareness among journalists and media managers of weaknesses in their coverage and encourage more comprehensive reporting.

The website compares the performance of various media outlets, with the aim, once enough stories are analysed, of feeding back comparative data to each outlet.

The group's spokesman, Professor David Henry, professor of clinical pharmacology at the University of Newcastle, said that unlike other services, such as Hitting the Headlines (www.nelh.nhs.uk), Media Doctor aimed to evaluate journalism rather than the evidence behind stories.

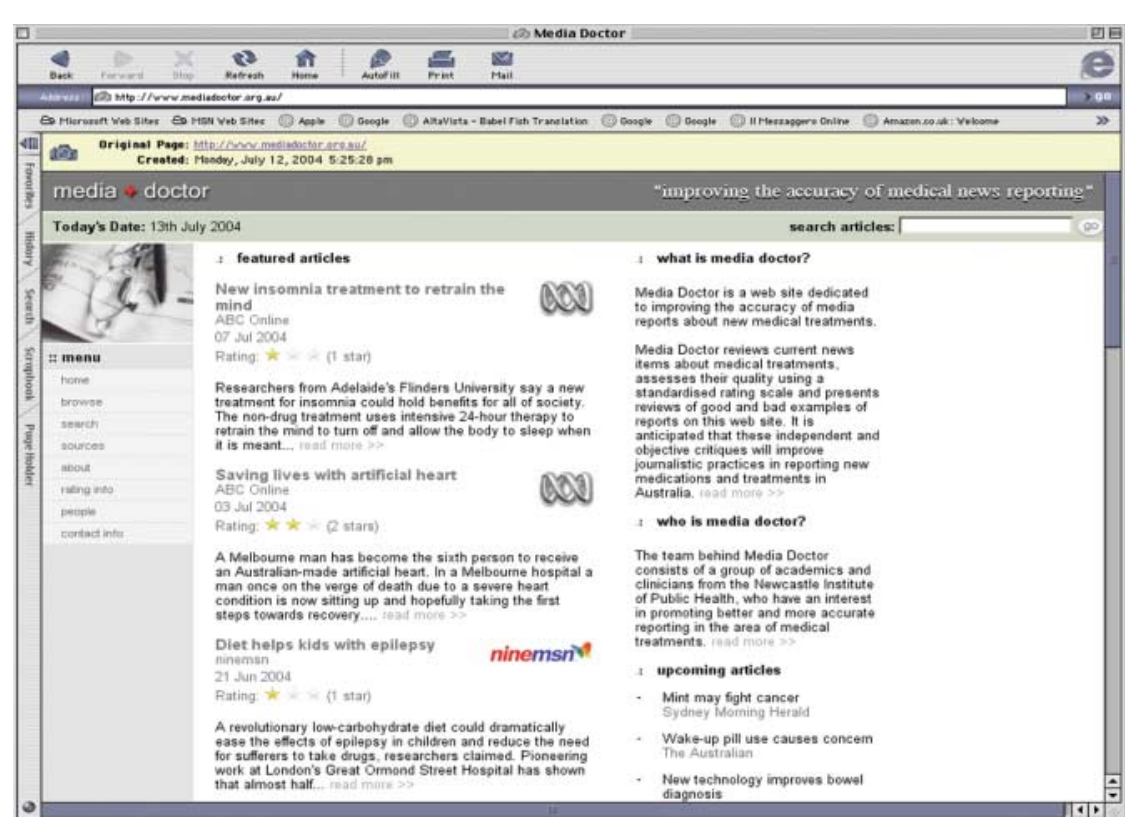

The site uses a three star rating system to evaluate media articles
The team intends to measure the site's impact on media coverage and is keen to collaborate internationally, especially in developing countries. "We'd like a minimum consistent data set collected in each country so we can do some inter-country comparisons," said Professor Henry.

The group had been tentative about publicising the new site, expecting it might be negatively received, but had been surprised by the level of positive media interest, he said.

"The lay media are the main route by which information about new products gets to the public and gets to doctors," said Professor Henry. "Under these circumstances, the journalists who write these pieces have got a special responsibility.'

Media and health professionals generally have welcomed the site, but some also had reservations about its approach. Many said that its lack of timeliness - it has a minimum two week turnaround-meant it would be more useful for journalism students than working journalists or others trying to interpret coverage of a current issue.

Katherine Baverstock, a pharmacist doing a PhD at the University of South Australia on media portrayal of medicines, said the site did not acknowledge the different world views of the media and scientists. "Surely the first way of improving medical writing is to broach that cultural divide and improve communication, so that each group understands the other-and the scientists would have to work hardest at this," she said. "Improving the quality of medical writing requires multiple strategies, hopefully originating and owned by the journalists for them to have any chance of working."

Hilda Bastian, managing editor of Informed Health Online, also believed the site did not sufficiently acknowledge the difference between media and scientific perspectives. "How you write a scientific paper$$
\text { time }
$$
keting. There were plans to improve timeliness and content, he said.

While it is too early to judge the site's impact on media coverage, it has already attracted international interest. Alan Cassels, a researcher running workshops to improve reporting of drugs in Canada (www.policyalternatives.ca/bc/drugs/ drugs journalists.html), believes that Media Doctor will be internationally useful. It showed, he said, that "thoughtful health decision makers know that we can no longer ignore the absolute impact of the media in shaping people's perceptions of health and health technologies."

Melissa Sweet freelance journalist specialising in health and medicine in Australia sweetcom@tig.com.au 


\section{Resisting cookbook medicine}

"I

$t$ is now the standard of care that every postmenopausal woman be given replacement hormones for the rest of her life unless there is a medical reason not to; to practise otherwise may be considered malpractice." These words, passionately spoken at a 2001 medical education conference by a foremost authority on women's health, left some listeners feeling uneasy. Unable to find randomised controlled trials that validated the presumed benefits of long term hormone replacement therapy (HRT), we concluded that HRT for disease prevention represented an experiment on women.

Today, two years after the release of the results of the women's health initiative study showing that HRT has more potential for harm than for good in healthy postmenopausal women taking a combination of oestrogen and progestogen to prevent chronic disease, the questions of 2001 remain relevant. Do individual doctors have the freedom to critically analyse available evidence and make management decisions that are based on informed reading of the literature and clinical experience? And, as medicine is essentially "work in progress," how do we foster healthy tension between doctors' autonomy and the "stand-

The HRT fiasco highlights the progressive role of thoughtful dissent ard of care"?

Accountability and acceptable standards of practice are prerequisites for self governing professions such as medicine. To try to ensure acceptable standards in an era of rapidly proliferating information and treatments, clinical practice guidelines have increasingly been implemented. While there are benefits to providing specific recommendations to doctors, the routine use of predetermined directives threatens to reduce doctors to practising "cookbook medicine"-thus contributing, perhaps, to increasing disillusionment within the profession, as the art of medicine is slowly eroded by management protocols. Furthermore, medical administrators and expertsincluding lawyers in search of "lucrative lapses"-are using standardised guidelines as templates to measure doctors' clinical performance.

Two things need to be borne in mind when considering the influence of experience and informed reading on doctors' decision making: the time lag between medical discovery and clinical implementation, and the documented influence of industry. In his book Helicobacter Pioneers Barry Marshall, one of the doctors who identified the link between $H$ pylori and ulcer disease, reflected on his slow and difficult journey of bringing about change in the medical community: "Was gastroenterdevelopment. ology a science or a religion? I decided it was the latter." Although accepted patterns of practice provide reassurance and stability, it is research based dissonance and openness to exploring new ideas that move medicine forward.

In 2001, when many people were trumpeting the benefits of HRT, it was troubling to find that there was little evidence supporting the safety of long term HRT; in fact much of the literature suggested concern. So what had catapulted HRT into the limelight to such a degree that it had become a top selling treatment?

Although the question is complex, the history of involvement of corporate interests in the development and promotion of long term preventive HRT is extensive. While medicine has long had a mutually profitable relationship with industry, this alliance has grown ever more uneasy as an increasing number of individual researchers, faculty members, and even academic institutions have developed close financial ties to companies whose products they are studying. Industry is influencing the research process in other ways: it influences the research questions that are chosen, methodology of studies, data analysis, whether results are published, and dissemination of results. It has even been found that some clinical practice guidelines and statements from "consensus conferences" are being indirectly funded by industry through grants to individuals and to specific foundations.

As translation of knowledge into clinical practice is often slow, and because medical dogma has been proved wrong on many occasions, it is critical that practitioners retain the freedom to pursue evidence based scientific fact. Balancing doctors' autonomy with care guidelines is thus particularly relevant. Doctors have a responsibility to scrutinise and integrate into practice new information and trends in medical management. Evaluating and using research findings in daily clinical practice is, undoubtedly, a lifelong part of professional

The HRT fiasco eloquently illustrates the potential shortcomings of doctrinaire clinical directives and highlights the progressive role of thoughtful dissent in the evolution of medical thought. Perhaps it is time to re-evaluate the tendency to regard authoritative documents as dogma and time to foster a healthy tension between autonomy and professional standards.

Stephen J Genuis associate professor

Shelagh K Genuis health researcher, University of Alberta,Canadasgenuis@ualberta.ca
SOUNDINGS

\section{Gulliver and bmj.com}

Suppose that Jonathan Swift published Gulliver's Travels in the BMJ. Within hours the rapid responses have begun to appear.

The first one anticipates Thackeray, in whose judgment the book was "Filthy in word, filthy in thoughts, furious, raging, and obscene." Moral outrage is followed by the scoffing of seafarers, geographers, and meteorologists pointing out that the tale is mere fantasy.

An engineer submits his calculations, according to which 1500 horses 4 inches high could not have drawn the carriage on to which Gulliver was fastened.

The human rights movement condemns the author for making fun of Lilliputians, people who were disadvantaged in growth. A rapid responder uses the words "dwarf" and "unnatural."

Hell breaks loose. For two days rapid responders are hurling insults at each other. The World Federation of Acromegalics protests, claming that the description of the people of Brobdingnag is insulting to them. The animal welfare people deplore the mention of a cage.

Before long, rapid responders begin to refer to the Bible, some of them misquoting it and most of them interpreting it liberally.

One responder expands upon the subaquatic sexual attack of the young Yahoo female and discusses the positions in which the two would have been joined were it not that upon Gulliver's frightened roaring the nag came galloping and chased her away.

By the fifth day the row about what is and is not natural has been revived, the electronic debate has become global, and there is lively participation of people from the former colonies.

So far there is one lonely voice who suspects that the writer may have had his tongue "deeply in his cheek," but on the fifth day a Dominican is wondering why doctors do not appreciate irony and a

New Yorker recognises the style of Swift.

Swift alerts his circle of friends so that they do not miss the comedy. He reiterates his conviction: Aristotle was wrong in assuming that the human is a rational animal; while homo is capable of rationality, it eschews the use of this faculty most of the time.

There is one single syllable rapid response that remains ignored by the respondents but gives the good dean food for thought: this is the word "eh?"

Imre Loefler editor, Nairobi Hospital Proceedings, Kenya 